\title{
Adenohypophyseal function in bitches treated with medroxyprogesterone acetate
}

\author{
N.J. Beijerink ${ }^{a}, *, 1$, S.F.M. Bhatti ${ }^{b, 1}$, A.C. Okkens ${ }^{\text {a }}$, S.J. Dieleman ${ }^{c}$, \\ J.A. Mol ${ }^{\text {a }}$, L. Duchateau ${ }^{\text {d, L.M.L. Van Ham }}{ }^{\text {b }}$, H.S. Kooistra ${ }^{a}$ \\ a Department of Clinical Sciences of Companion Animals, Faculty of Veterinary Medicine, \\ Utrecht University, Utrecht, The Netherlands \\ ${ }^{\mathrm{b}}$ Department of Small Animal Medicine and Clinical Biology, Faculty of Veterinary Medicine, \\ Ghent University, Merelbeke, Belgium \\ ${ }^{\mathrm{c}}$ Department of Farm Animal Health, Section of Reproduction, Faculty of Veterinary Medicine, \\ Utrecht University, Utrecht, The Netherlands \\ ${ }^{\mathrm{d}}$ Department of Physiology and Biometrics, Faculty of Veterinary Medicine, \\ Ghent University, Merelbeke, Belgium
}

Received 9 November 2005; received in revised form 21 December 2005; accepted 21 December 2005

\begin{abstract}
The aim of this study was to investigate the effects of treatment with medroxyprogesterone acetate (MPA) on canine adenohypophyseal function. Five Beagle bitches were treated with MPA $(10 \mathrm{mg} / \mathrm{kg}$, every 4 weeks) and their adenohypophyseal function was assessed in a combined adenohypophyseal function test. Four hypophysiotropic hormones (CRH, GHRH, GnRH, and TRH) were administered before and 2, 5, 8, and 11 months after the start of MPA treatment, and blood samples for determination of the plasma concentrations of ACTH, cortisol, GH, IGF-1, LH, FSH, prolactin, $\alpha-\mathrm{MSH}$, and TSH were collected at $-15,0,5,10,20,30$, and 45 min after suprapituitary stimulation.

MPA successfully prevented the occurrence of estrus, ovulation, and a subsequent luteal phase. MPA treatment did not affect basal and GnRH-induced plasma LH concentrations. The basal plasma FSH concentration was significantly higher at 2 months after the start of MPA treatment than before or at 5, 8, and 11 months after the start of treatment. The maximal FSH increment and the AUC for FSH after suprapituitary stimulation were significantly higher before treatment than at 5, 8, and 11

\footnotetext{
* Corresponding author at: Department of Clinical Sciences of Companion Animals, Faculty of Veterinary Medicine, Utrecht University, Yalelaan 8, PO Box 80154, NL-3508 TD Utrecht, The Netherlands. Tel.: +31 30 2531680; fax: +31302539393.

E-mail address: N.J.Beijerink@vet.uu.nl (N.J. Beijerink).

1 Both authors contributed equally to the article.
} 
months of MPA treatment. Differences in mean basal plasma GH concentrations before and during treatment were not significant, but MPA treatment resulted in significantly elevated basal plasma IGF- 1 concentrations at 8 and 11 months. MPA treatment did not affect basal and stimulated plasma ACTH concentrations, with the exception of a decreased AUC for ACTH at 11 months. In contrast, the maximal cortisol increment and the AUC for cortisol after suprapituitary stimulation were significantly lower during MPA treatment than prior to treatment. MPA treatment did not affect basal plasma concentrations of prolactin, TSH, and $\alpha-\mathrm{MSH}$, with the exception of slightly increased basal plasma TSH concentrations at 8 months of treatment. MPA treatment did not affect TRH-induced plasma concentrations of prolactin and TSH.

In conclusion, the effects of chronic MPA treatment on adenohypophyseal function included increased FSH secretion, unaffected LH secretion, activation of the mammary GH-induced IGF-I secretion, slightly activated TSH secretion, suppression of the hypothalamic-pituitary-adrenocortical axis, and unaffected secretion of prolactin and $\alpha-\mathrm{MSH}$.

(c) 2006 Elsevier Inc. All rights reserved.

Keywords: Progestins; Gonadotropins; ACTH and cortisol; GH and IGF-1; Pituitary; Dog

\section{Introduction}

Progestins, such as medroxyprogesterone acetate (MPA), are commonly used to prevent estrus in the bitch [1,2]. Whether the estrus-preventing properties of progestins in the bitch are due to effects on the hypothalamus, on the pituitary gland, or at the ovarian level is not clear. McCann et al. [3] and Colon et al. [4] reported that basal plasma levels of luteinizing hormone ( $\mathrm{LH})$ and follicle-stimulating hormone (FSH) do not change during progestin treatment. Information about the effect of gonadotropin-releasing hormone $(\mathrm{GnRH})$ on the secretion of LH during progestin treatment is conflicting. GnRH-induced increases in plasma LH concentrations in progestin-treated dogs did not differ from those in control dogs in one study [4], while in another study the GnRH-induced LH levels were reduced [3]. In dogs there is no information on the effect of progestins on GnRH-stimulated FSH concentrations.

In women, progestins are known to prevent ovulation by inhibiting the mid-cycle surges of FSH and $\mathrm{LH}$, whereas the tonic release of these gonadotropins continues at luteal phase levels $[5,6]$. Long-term use of depot MPA in women does not affect the pituitary responsiveness of LH and FSH to GnRH administration, suggesting that the pituitary is not the primary site for ovulation inhibition in women [7].

Prolonged treatment with progestins in bitches is associated with alterations in the release of pituitary hormones other than gonadotropins. Progestin administration leads to a decrease in the pituitary responsiveness of growth hormone $(\mathrm{GH})$ to growth hormone releasing hormone (GHRH) [8-10]. This change is due to GH release from foci of hyperplastic ductular mammary epithelium [11,12], leading to elevated plasma GH levels that do not have a pulsatile plasma profile [8]. The hypothalamic-pituitary-adrenocortical (HPA) axis is suppressed by progestins $[3,13,14]$, due to the intrinsic glucocorticoid properties of progestins [14-16]. While basal plasma concentrations of adrenocorticotropic hormone (ACTH) are only moderately affected [14], the basal plasma concentrations of cortisol are markedly decreased $[3,14,17,18]$. In addition, the response of ACTH and cortisol to stimulation with 
corticotropin-releasing hormone $(\mathrm{CRH})$ may be reduced $[3,14]$. Also, in women the administration of MPA causes suppression of the HPA axis [19].

With regard to other anterior pituitary hormones, such as prolactin and $\mathrm{TSH}$, there is little information about the effect of progestin treatment on their release. In the bitch, progestin treatment does not seem to affect mean prolactin [17] and TSH concentrations [20]. Information with regard to pituitary responsiveness of prolactin to suprapituitary stimulation is limited to one study, in which MPA administration did not change prolactin response to TRH in ovariohysterectomized, estradiol-primed bitches [13]. On the other hand, there is evidence that treatment with MPA increases the pituitary prolactin responsiveness to TRH in women [21]. Finally, there are no reports on the effect of progestins on the pituitary release of $\alpha$-melanocyte-stimulating hormone ( $\alpha$-MSH).

The aim of the present study was to obtain an integral picture of the effect of progestins on the function of the adenohypophysis in the bitch. For this purpose, the effects of suprapituitary stimulation on the release of seven adenohypophyseal hormones were studied before and several times during MPA treatment in Beagle bitches by means of a combined anterior pituitary function test $[22,23]$.

\section{Materials and methods}

\subsection{Animals}

Studies were carried out in five healthy intact Beagle bitches, aged 3-9 years and weighing $9.0-10.3 \mathrm{~kg}$, that never had been treated with progestins. They were housed in pens with outdoor access, fed a commercial diet once daily, and given water ad libitum. They were accustomed to the laboratory environment and procedures such as collection of blood samples. Throughout the study the general condition of the dogs was monitored by physical examination and routine clinical chemistry.

\subsection{Experimental protocol}

In the dogs used in this study, the tip of the right uterine horn and the corresponding ovary had been excised to serve as control tissues in another study. This surgical procedure had been performed $245 \pm 42$ days (mean \pm S.D.) before the start of the treatment with MPA. After the surgery, all of the dogs had had one complete estrous cycle.

Treatment with the synthetic progestin depot preparation MPA (Depo-Promone ${ }^{\circledR}$, Pharmacia Animal Health, Puurs, Belgium) was begun during anestrus in a dose of $10 \mathrm{mg} / \mathrm{kg}$ body weight subcutaneously at intervals of 4 weeks, for a total of 13 injections. Three days before the start of the treatment with MPA, the mean plasma progesterone concentration was $0.9 \pm 0.3 \mathrm{nmol} / \mathrm{L}$ (mean \pm S.D.).

Before and at 2, 5, 8, and 11 months after the start of the treatment with MPA, a combined anterior pituitary function test was performed using four releasing hormones (4RH test) according to methods described previously [22,23]. Briefly, an intravenous catheter was placed in the cephalic vein of each dog to facilitate rapid sequential injection. Immediately after the collection of the zero blood sample from the jugular vein, four releasing 
hormones were injected intravenously within $30 \mathrm{~s}$, in the following order and doses per $\mathrm{kg}$ body weight: $1 \mu \mathrm{g}$ oCRH (Peninsula Laboratories Inc., Belmont, CA, USA), $1 \mu \mathrm{g}$ hGHRH (hGHRF; Peninsula Laboratories Inc., Belmont, CA, USA), $10 \mu \mathrm{g} \mathrm{GnRH} \mathrm{(Fertagyl}{ }^{\circledR}$; Intervet, Boxmeer, The Netherlands), and $10 \mu \mathrm{g}$ TRH (Hoffman-La Roche, Basel, Switzerland). During progestin treatment, the $4 \mathrm{RH}$ tests were always performed immediately before the next 4-weekly administration of MPA. The clock for blood sampling was started immediately after the administration of the last releasing hormone. Blood samples were collected at $-15,0,5,10,20,30$, and $45 \mathrm{~min}$ from the jugular vein and transferred to ice-chilled EDTAcoated and heparinized (for TSH) tubes. Samples were centrifuged at $4^{\circ} \mathrm{C}$ for $10 \mathrm{~min}$. Plasma was stored at $-25^{\circ} \mathrm{C}$ until assayed for ACTH, cortisol, GH, FSH, LH, prolactin, and TSH. Plasma concentrations of $\alpha-\mathrm{MSH}$ and IGF-1 were determined in the -15 and 0 min samples only.

\subsection{Hormone determinations}

Plasma progesterone concentration was measured by a previously validated radioimmunoassay (RIA) [24]. The sensitivity of the assay was $0.005 \mathrm{ng}$. The intra-assay and interassay coefficients of variation $(\mathrm{CV})$ were 7.05 and $8.75 \%$, respectively.

Plasma ACTH concentration was measured by use of a two-site immunoradiometric assay (IRMA) (Nichols Institute, Wijchen, The Netherlands) as described previously [25]. The antiserum is highly specific for $\mathrm{ACTH}_{1-39}$. The intra-assay and interassay $\mathrm{CV}$ were 3.2 and $7.8 \%$, respectively, and the lower limit of quantitation was $0.22 \mathrm{pmol} / \mathrm{L}$. The antiserum cross-reacts with neither $\alpha-\mathrm{MSH}$ nor ACTH precursors [26,27].

Plasma cortisol concentration was measured by an RIA validated for the dog (Coat-ACount ${ }^{\circledR}$ Cortisol, Diagnostic Product Corporation, Los Angeles, CA, USA) as described previously [28]. Intra-assay and interassay CV ranged from 3.0 to 5.1 and from 4.0 to $6.4 \%$, respectively. The lower limit of quantitation was $1 \mathrm{nmol} / \mathrm{L}$.

Plasma FSH concentration was measured by a homologous canine IRMA (AHC004, Biocode SA, Liège, Belgium). The intra-assay and interassay CV for values above $1.6 \mu \mathrm{g} / \mathrm{L}$ were 3.2 and $15 \%$, respectively. The lower limit of quantitation was $1.5 \mu \mathrm{g} / \mathrm{L}$.

Plasma GH concentration was measured by a commercially available RIA for porcine and canine GH according to the manufacturer's protocol (PGH-46HK; Linco Research, St. Charles, MS, USA). The interassay CV was $7.6 \%$ at a plasma concentration of $4.4 \mu \mathrm{g} / \mathrm{L}$. Cross reactivity of porcine prolactin and human GH was less than $0.5 \%$. Recovery of porcine $\mathrm{GH}$, which is identical to canine $\mathrm{GH}$, in canine serum averaged $104 \pm 14 \%$ (mean \pm S.D.). Dilution of a canine plasma sample containing high endogenous GH concentrations revealed parallelism to the standard curve. The lower limit of quantitation was $1.0 \mu \mathrm{g} / \mathrm{L}$.

Plasma total IGF-1 concentration was measured by a heterologous RIA, validated for the dog, after acid-ethanol extraction to remove interfering IGF binding proteins (IGFBPs). Plasma IGF was extracted using a mixture of $87.5 \%(\mathrm{v} / \mathrm{v})$ ethanol and $12.5 \% 2 \mathrm{M}$ formic acid. Tubes containing $100 \mu \mathrm{l}$ plasma and $400 \mu \mathrm{l}$ of the ethanol-formic acid mixture were mixed thoroughly and incubated for $30 \mathrm{~min}$ at room temperature. After centrifugation for $30 \mathrm{~min}$ at $5500 \times g$ at $4{ }^{\circ} \mathrm{C}$, a $50 \mu \mathrm{l}$ aliquot of the supernatant was diluted 1:50 with assay buffer containing $63 \mathrm{mM} \mathrm{Na}_{2} \mathrm{HPO}_{4}(\mathrm{pH} 7.4), 13 \mathrm{mM} \mathrm{Na} 2$ EDTA, and $0.25 \%$ (w/v) BSA. 
The extraction efficiency was $92.5 \pm 5.7 \%$ [29]. The intra-assay and interassay CV were $8.6 \%$ and $13.4 \%$ at a plasma concentration of 100 and $73 \mu \mathrm{g} / \mathrm{L}$, respectively. The lower limit of quantitation was $10 \mu \mathrm{g} / \mathrm{L}$. IGF-1 antiserum AFP4892898 and human IGF-1 for iodination were obtained from the National Hormone and Peptide Program (Harbor-UCLA Medical Center, Torrance, CA).

Plasma LH concentration was measured by a heterologous RIA described previously by Nett et al. [30], with a few modifications. A rabbit antiserum raised against ovine LH (CSU-204, kindly supplied by G.D. Niswender, Colorado State University, CO, USA), radio-iodinated bovine LH-7981 as prepared for our bovine LH assay [31], and canine pituitary standard LER 1685-1 (a gift of Dr. L.E. Reichert, Albany Medical College, NY, USA) were used in this assay. The intra-assay and interassay CV for values above $0.5 \mu \mathrm{g} / \mathrm{L}$ were 2.3 and $10.5 \%$, respectively. The lower limit of quantitation was $0.3 \mu \mathrm{g} / \mathrm{L}$.

Plasma $\alpha$-MSH concentration was measured by RIA without extraction according to methods described previously [32]. The intra-assay and interassay CV were less than 8 and $23 \%$, respectively. The lower limit of quantitation was $5 \mathrm{pmol} / \mathrm{L}$.

Plasma prolactin concentration was measured by a previously validated heterologous RIA [33]. The intra-assay and interassay CV were 3.5 and $11.5 \%$, respectively. The lower limit of quantitation was $0.8 \mu \mathrm{g} / \mathrm{L}$.

Plasma TSH concentration was determined by a homologous solid-phase, two-site chemiluminescent enzyme immunometric assay (Immulite Canine TSH Diagnostic Products Corporation (DPC), Los Angeles, CA) according to the instructions of the manufacturer as described previously [34]. The intra-assay CV were 5.0, 4, and 3.8\% at TSH levels of $0.20,0.50$, and $2.6 \mu \mathrm{g} / \mathrm{L}$, respectively. The interassay $\mathrm{CV}$ were 6.3 and $8.2 \%$ at TSH levels of 0.16 and $2.8 \mu \mathrm{g} / \mathrm{L}$, respectively. The lowest detectable amount of TSH was $0.03 \mu \mathrm{g} / \mathrm{L}$. Cross reactivity with FSH and LH was negligible. The upper limit of the reference range for the plasma TSH concentration in euthyroid dogs is $0.6 \mu \mathrm{g} / \mathrm{L}$.

\subsection{Data analysis}

Analyses were performed with SAS version 9.1 for Windows (Insightful Corp., Seattle, WA, USA). Differences in body weight before and after the study were assessed in a paired Student's $t$-test. Plasma $\alpha$-MSH concentrations below the limit of quantitation were assigned a value of $5 \mathrm{pmol} / \mathrm{L}$. The following response variables were considered: basal hormone value, maximal increment from basal level, and area under the curve above the basal hormone level (AUC). The basal concentration was defined as the mean of the hormone concentrations at -15 and $0 \mathrm{~min}$. The AUC for hormone concentration following stimulation was calculated by the trapezoidal method. Basal hormone concentration, maximal increment, and AUC before and after MPA treatment were compared for the different hormone concentrations using a mixed model with dog as random effect and period $(0,2,5,8$, and 11 months after MPA treatment) as categorical fixed effects factor. The periods were compared in pairs, applying Tukey's multiple comparisons technique at a global significance level of 5\% to obtain adjusted $P$ values.

Additionally, a mixed model was used with dog as random effect and period, time (minutes after stimulation) and the period by time interaction as categorical fixed effects 
to investigate whether the time evolution after stimulation differed from period to period.

\subsection{Ethics of experimentation}

The study protocol was approved by the Ethical Committee of the Faculty of Veterinary Medicine, Ghent University, Belgium.

\section{Results}

No signs of estrus were detected during the 12 months of MPA treatment. In addition, plasma progesterone concentrations were low at 5 months $(0.6 \pm 0.6 \mathrm{nmol} / \mathrm{L}$; mean \pm S.D. $)$ and 12 months $(0.6 \pm 0.3 \mathrm{nmol} / \mathrm{L})$ after the start of the treatment. The mean body weight of the dogs on the day of the last injection of MPA $(12.4 \pm 1.6 \mathrm{~kg}$, mean \pm S.D.) was significantly higher $(P=0.02)$ than that on the day of the first injection of MPA $(9.5 \pm 0.7 \mathrm{~kg})$.

Basal plasma LH concentrations did not change significantly. In each sampling period, suprapituitary stimulation resulted in a significant rise $(P<0.001)$ in plasma LH concentration. The maximal increment and the AUC for LH did not vary significantly with time (Table 1, Fig. 1).

Basal plasma FSH concentration was significantly higher at 2 months after the start of treatment with MPA than before treatment $(P=0.004)$ or at $5(P=0.004), 8(P=0.002)$, or 11 months $(P<0.001)$ after the start of the treatment. In each sampling period, suprapituitary stimulation resulted in a significant rise $(P<0.001)$ in the plasma FSH concentration. The maximal increment was significantly higher before treatment than after $5(P=0.01)$ or 11 months $(P=0.01)$ of treatment with MPA, while it tended to be higher $(P=0.07)$ at 8 months. The AUC for FSH was significantly higher before MPA treatment than after $5(P<0.001)$, $8(P=0.03)$, or $11(P=0.02)$ months of treatment with MPA (Table 1, Fig. 1$)$.

Differences in basal plasma GH concentration before and during treatment with MPA were not significant. At 8 months after the start of treatment with MPA suprapituitary stimulation resulted in a significant rise $(P<0.001)$ in plasma $\mathrm{GH}$ concentration, while no significant effect was noted during the other periods. Differences in the maximal increment and the AUC for GH before and during the treatment with MPA were not significant (Table 2, Fig. 2). Basal plasma IGF-1 concentration was significantly higher at 8 months $(P=0.02)$ and 11 months $(P<0.001)$ of treatment with MPA than before treatment. In addition, basal plasma IGF-1 concentration was significantly higher at 11 months of treatment than at 2 months $(P=0.02)$ (Table 2).

Differences in basal plasma ACTH concentration before and during treatment with MPA were not significant. In each sampling period, suprapituitary stimulation resulted in a significant rise $(P<0.001)$ in plasma ACTH concentration. Differences in the maximal increment before and during the treatment with MPA were not significant. The AUC for ACTH after 11 months of MPA treatment was significantly lower $(P=0.05)$ than at 2 and 8 months after the start of the MPA treatment (Table 3, Fig. 3). Differences in basal plasma cortisol concentration before and during treatment with MPA were not significant. In each sampling period, suprapituitary stimulation resulted in a significant rise $(P<0.001)$ in plasma 
Table 1

Characteristics of LH and FSH secretion in five Beagle bitches in a combined anterior pituitary function test [22,23] before and 2, 5, 8, and 11 months after starting treatment with MPA

\begin{tabular}{llllll}
\hline & Before treatment & \multicolumn{4}{l}{ Months after starting treatment with MPA } \\
\cline { 3 - 6 } & & 2 & 5 & 8 & 11 \\
\hline LH basal $(\mu \mathrm{g} / \mathrm{L})$ & $3.0 \pm 1.2$ & $4.6 \pm 1.9$ & $2.9 \pm 0.6$ & $3.9 \pm 2.1$ & $2.5 \pm 1.1$ \\
LH increment $(\mu \mathrm{g} / \mathrm{L})$ & $57.4 \pm 9.3$ & $58.3 \pm 8.9$ & $62.3 \pm 10.6$ & $82.9 \pm 21.3$ & $82.0 \pm 19.3$ \\
LH $T_{\max }(\min )$ & $10,5-20$ & $10,10-20$ & $10,10-20$ & $10,10-20$ & $10,10-20$ \\
LH AUC $(\mu \mathrm{g} / \mathrm{L} \times 45 \mathrm{~min})$ & $1633 \pm 262$ & $1801 \pm 363$ & $1797 \pm 302$ & $2019 \pm 558$ & $2024 \pm 386$ \\
FSH basal $(\mu \mathrm{g} / \mathrm{L})$ & $7.4 \pm 0.9$ & $14.2 \pm 2.1^{\mathrm{a}}$ & $7.5 \pm 1.2$ & $6.9 \pm 1.2$ & $5.6 \pm 0.9$ \\
FSH increment $(\mu \mathrm{g} / \mathrm{L})$ & $27.2 \pm 4.3$ & $22.2 \pm 3.8$ & $17.6 \pm 3.2^{\mathrm{b}}$ & $20.2 \pm 4.1$ & $17.5 \pm 3.6^{\mathrm{b}}$ \\
FSH $T_{\max }(\min )$ & $20,10-20$ & $20,20-30$ & $20,20-45$ & $20,10-20$ & $20,10-20$ \\
FSH AUC $(\mu \mathrm{g} / \mathrm{L} \times 45 \mathrm{~min})$ & $932 \pm 137$ & $756 \pm 121$ & $599 \pm 116^{\mathrm{b}}$ & $645 \pm 135^{\mathrm{b}}$ & $608 \pm 118^{\mathrm{b}}$ \\
\hline
\end{tabular}

The values are expressed as mean \pm S.E.M. or median and range. $T_{\max }$ indicates the time at which maximal suprapituitary stimulation was observed.

a Significantly different from before treatment and at 5, 8, and 11 months after starting treatment with MPA.

b Significantly different from before MPA treatment.

cortisol concentration. The maximal increments decreased significantly during treatment ( $P=0.003, P=0.01, P=0.002$, and $P=0.002$, respectively). The AUC for cortisol in the four periods of treatment with MPA was significantly lower than that before MPA treatment ( $P=0.002, P=0.003, P=0.002$, and $P=0.002$, respectively) (Table 3, Fig. 3).
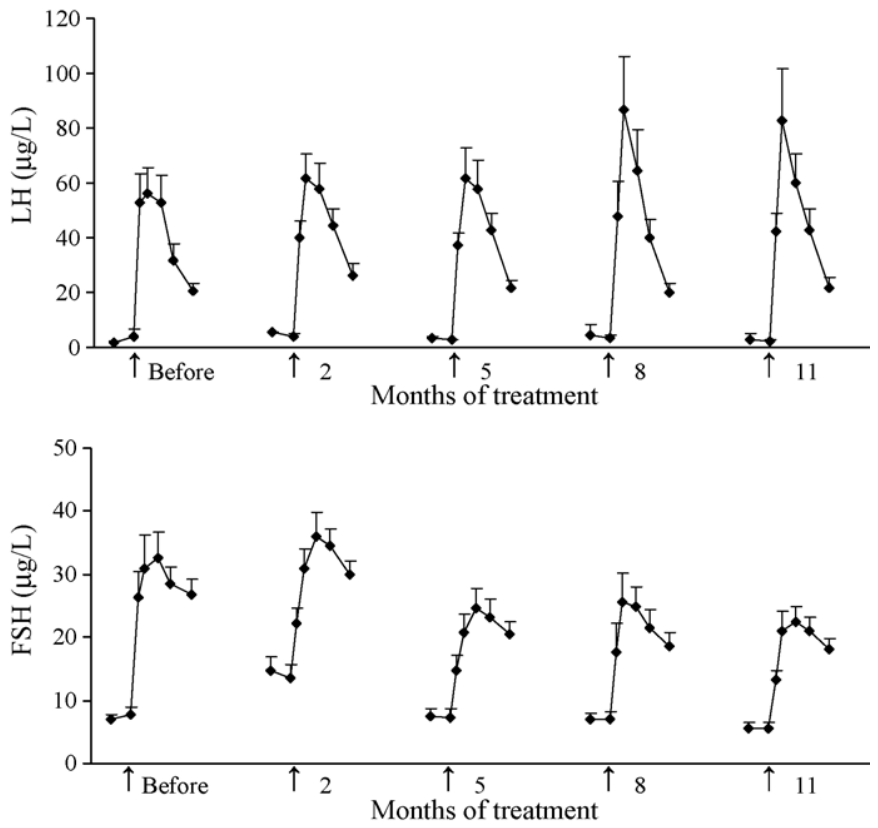

Fig. 1. Plasma LH and FSH responses (mean \pm S.E.M.) in five Beagle bitches in a combined anterior pituitary function test $[22,23]$ before and 2, 5, 8, and 11 months after starting treatment with MPA. Blood samples were collected at $-15,0,5,10,20,30$, and 45 min following the injection of the releasing hormones at 0 min (arrow). 
Table 2

Characteristics of GH and IGF-I secretion in five Beagle bitches in a combined anterior pituitary function test (see also legend to Table 1)

\begin{tabular}{llllll}
\hline & Before treatment & \multicolumn{4}{l}{ Months after starting treatment with MPA } \\
\cline { 3 - 6 } & & 2 & 5 & 8 & 11 \\
\hline GH basal $(\mu \mathrm{g} / \mathrm{L})$ & $2.7 \pm 0.9$ & $2.3 \pm 0.3$ & $2.5 \pm 0.3$ & $2.7 \pm 0.4$ & $3.0 \pm 0.5$ \\
GH increment $(\mu \mathrm{g} / \mathrm{L})$ & $1.8 \pm 1.5$ & $0.6 \pm 0.3$ & $0.9 \pm 0.4$ & $1.1 \pm 0.2$ & $0.6 \pm 0.4$ \\
GH $T_{\max }(\min )$ & $5,-15$ to 45 & $20,10-30$ & $10,-15$ to 20 & $20,5-45$ & $10,0-20$ \\
GH AUC $(\mu \mathrm{g} / \mathrm{L} \times 45 \mathrm{~min})$ & $5.1 \pm 44.4$ & $13.1 \pm 9.5$ & $23.3 \pm 17.6$ & $34.5 \pm 7.4$ & $12.4 \pm 13.7$ \\
IGF-I basal $(\mu \mathrm{g} / \mathrm{L})$ & $45.3 \pm 5.6$ & $108 \pm 24.6$ & $135 \pm 35.4$ & $159 \pm 29.8^{\text {a }}$ & $224 \pm 53.3^{\mathrm{a}, \mathrm{b}}$ \\
\hline
\end{tabular}

${ }^{a}$ Significantly different from before MPA treatment.

b Significantly different from 2 months after starting treatment with MPA.

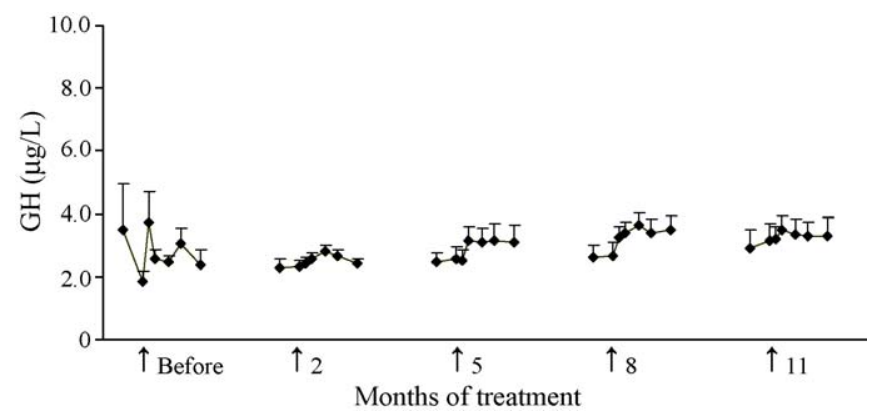

Fig. 2. Plasma GH responses (mean \pm S.E.M.) in five Beagle bitches in a combined anterior pituitary function test (see also legend to Fig. 1).

Differences in basal plasma prolactin concentration before and during treatment with MPA were not significant. In each sampling period, suprapituitary stimulation resulted in a significant rise $(P<0.001)$ in plasma prolactin concentration. Differences in the maximal increment and the AUC for prolactin before and during treatment with MPA were not significant (Table 4, Fig. 4).

Basal plasma TSH concentration at 8 months of MPA treatment was significantly higher than before treatment $(P=0.03)$ and at 5 months of treatment $(P=0.05)$. In each sampling period, suprapituitary stimulation resulted in a significant rise $(P<0.001)$ in plasma TSH concentration. Differences in the maximal increment and the AUC for TSH before and during MPA treatment were not significant (Table 4, Fig. 4).

Basal plasma $\alpha$-MSH concentration was $20.7 \pm 4.9 \mathrm{pmol} / \mathrm{L}$ before treatment and $20.3 \pm 5.3,21.3 \pm 5.3,25.6 \pm 8.4$, and $32.1 \pm 4.4 \mathrm{pmol} / \mathrm{L}$ at the four sampling times during MPA treatment. Differences in the mean plasma $\alpha-\mathrm{MSH}$ concentrations were not significant.

\section{Discussion}

The tip of one uterine horn and the corresponding ovary were used as control tissues in another study. Nevertheless, all bitches had an estrous cycle between the surgical procedure 
Table 3

Characteristics of ACTH and cortisol secretion in five Beagle bitches in a combined anterior pituitary function test (see also legend to Table 1)

\begin{tabular}{llllll}
\hline & \multirow{2}{*}{$\begin{array}{l}\text { Before } \\
\text { treatment }\end{array}$} & \multicolumn{4}{l}{ Months after starting treatment with MPA } \\
\cline { 3 - 6 } & & 2 & 5 & 8 & 11 \\
\hline ACTH basal (pmol/L) & $3.8 \pm 0.86$ & $6.0 \pm 0.68$ & $4.2 \pm 0.55$ & $5.3 \pm 0.35$ & $4.9 \pm 0.37$ \\
ACTH increment (pmol/L) & $68 \pm 14$ & $59 \pm 7.0$ & $47 \pm 4.6$ & $64 \pm 8.1$ & $42 \pm 7.0$ \\
ACTH $T_{\max }(\min )$ & $5,5-10$ & $10,5-30$ & $10,5-30$ & $10,5-10$ & $10,5-45$ \\
ACTH AUC (pmol/L $\times 45$ min) & $1840 \pm 286$ & $2005 \pm 212$ & $1498 \pm 94$ & $2027 \pm 180$ & $1276 \pm 231^{\mathrm{a}}$ \\
Cortisol basal $(\mathrm{nmol} / \mathrm{L})$ & $47.6 \pm 4.6$ & $60.1 \pm 11.4$ & $58.1 \pm 18.0$ & $52.5 \pm 9.90$ & $58.4 \pm 13.7$ \\
Cortisol increment $(\mathrm{nmol} / \mathrm{L})$ & $380 \pm 39.1$ & $238 \pm 12.1^{\mathrm{b}}$ & $258 \pm 19.1^{\mathrm{b}}$ & $231 \pm 24.3^{\mathrm{b}}$ & $226 \pm 16.2^{\mathrm{b}}$ \\
Cortisol $T_{\max }(\min )$ & $30,30-45$ & $30,30-45$ & $45,30-45$ & $30,20-45$ & $30,20-30$ \\
Cortisol AUC $(\mathrm{nmol} / \mathrm{L} \times 45 \mathrm{~min})$ & $12199 \pm 1121$ & $7825 \pm 331^{\mathrm{b}}$ & $8042 \pm 572^{\mathrm{b}}$ & $7785 \pm 707^{\mathrm{b}}$ & $7585 \pm 433^{\mathrm{b}}$ \\
\hline
\end{tabular}

a Significantly different from 2 and 8 months after starting treatment with MPA.

b Significantly different from before MPA treatment.

and the start of the MPA treatment. Chaffaux et al. [35] demonstrated in dogs that basal plasma gonadotropin levels and the response of these hormones to an intramuscular injection of a GnRH analogue were unaffected by unilateral ovariectomy. Furthermore, the difference in plasma FSH concentration between intact and unilateral oophorectomized women was not significant [36]. Thus the dogs used in this study can be regarded as having an intact hypothalamus-pituitary-ovarian axis.
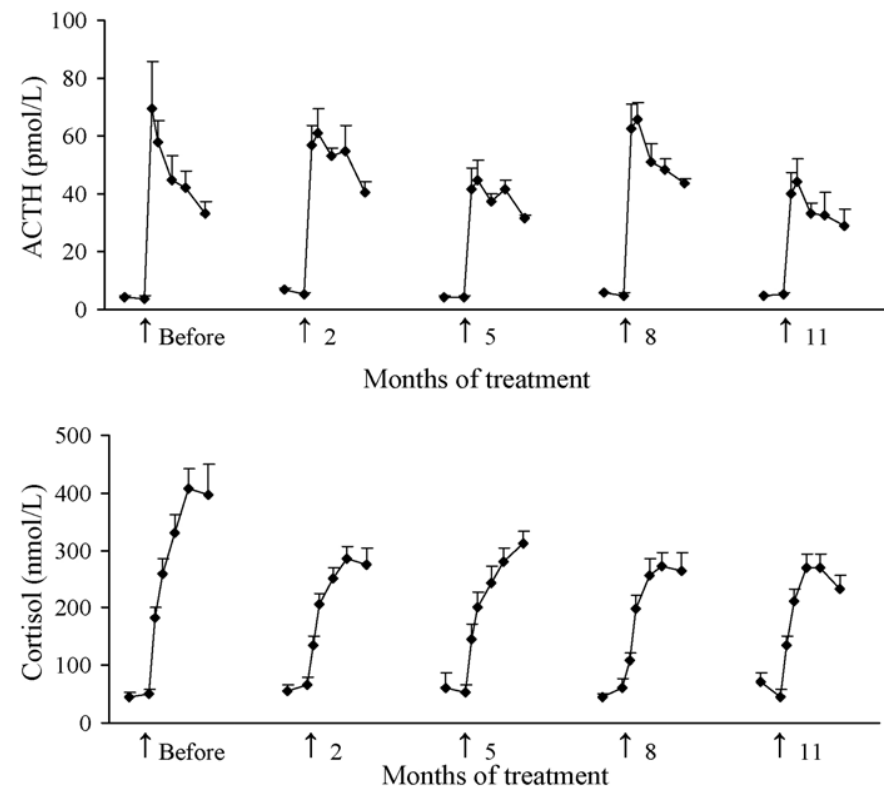

Fig. 3. Plasma ACTH and cortisol responses (mean \pm S.E.M.) in five Beagle bitches in a combined anterior pituitary function test (see also legend to Fig. 1). 
Table 4

Characteristics of TSH and prolactin secretion in five Beagle bitches in a combined anterior pituitary function test (see also legend to Table 1)

\begin{tabular}{llllll}
\hline & Before treatment & \multicolumn{4}{l}{ Months after starting treatment with MPA } \\
\cline { 3 - 6 } & & 2 & 5 & 8 & 11 \\
\hline TSH Basal $(\mu \mathrm{g} / \mathrm{L})$ & $0.09 \pm 0.03$ & $0.21 \pm 0.06$ & $0.14 \pm 0.04$ & $0.22^{\mathrm{a}} \pm 0.08$ & $0.17 \pm 0.07$ \\
TSH increment $(\mu \mathrm{g} / \mathrm{L})$ & $0.76 \pm 0.25$ & $1.01 \pm 0.21$ & $0.88 \pm 0.17$ & $1.13 \pm 0.27$ & $0.91 \pm 0.25$ \\
TSH $T_{\max }(\min )$ & $10,5-20$ & $20,10-30$ & $30,10-30$ & $10,10-20$ & $10,10-30$ \\
TSH AUC $(\mu \mathrm{g} / \mathrm{L} \times 45 \mathrm{~min})$ & $23.4 \pm 6.13$ & $34.1 \pm 7.95$ & $30.0 \pm 5.57$ & $36.2 \pm 7.62$ & $28.7 \pm 6.09$ \\
PRL basal $(\mu \mathrm{g} / \mathrm{L})$ & $8.51 \pm 2.49$ & $9.07 \pm 3.17$ & $11.3 \pm 6.74$ & $4.73 \pm 0.83$ & $7.95 \pm 2.49$ \\
PRL increment $(\mu \mathrm{g} / \mathrm{L})$ & $53.2 \pm 18.0$ & $42.4 \pm 14.3$ & $28.5 \pm 7.2$ & $66.2 \pm 20.1$ & $33.2 \pm 6.6$ \\
PRL $T_{\max }(\min )$ & $10,5-20$ & $10,5-10$ & $10,5-20$ & $10,5-10$ & $10,5-20$ \\
PRL AUC $(\mu \mathrm{g} / \mathrm{L} \times 45 \mathrm{~min})$ & $1086 \pm 231$ & $1038 \pm 272$ & $698 \pm 211$ & $1418 \pm 260$ & $806 \pm 148$ \\
\hline
\end{tabular}

${ }^{\text {a }}$ Significantly different from before MPA treatment and at 5 months of MPA treatment.

The results of this study demonstrate that treatment with MPA affects the hypothalamicpituitary-ovarian axis. Estrus, ovulation, and a subsequent luteal phase did not occur in any of the bitches during treatment with MPA, as judged by the lack of external signs of estrus and low plasma levels of progesterone. Although the design followed in this study does not allow for a mechanistic examination of the mode of estrus suppression in the bitch, and thus
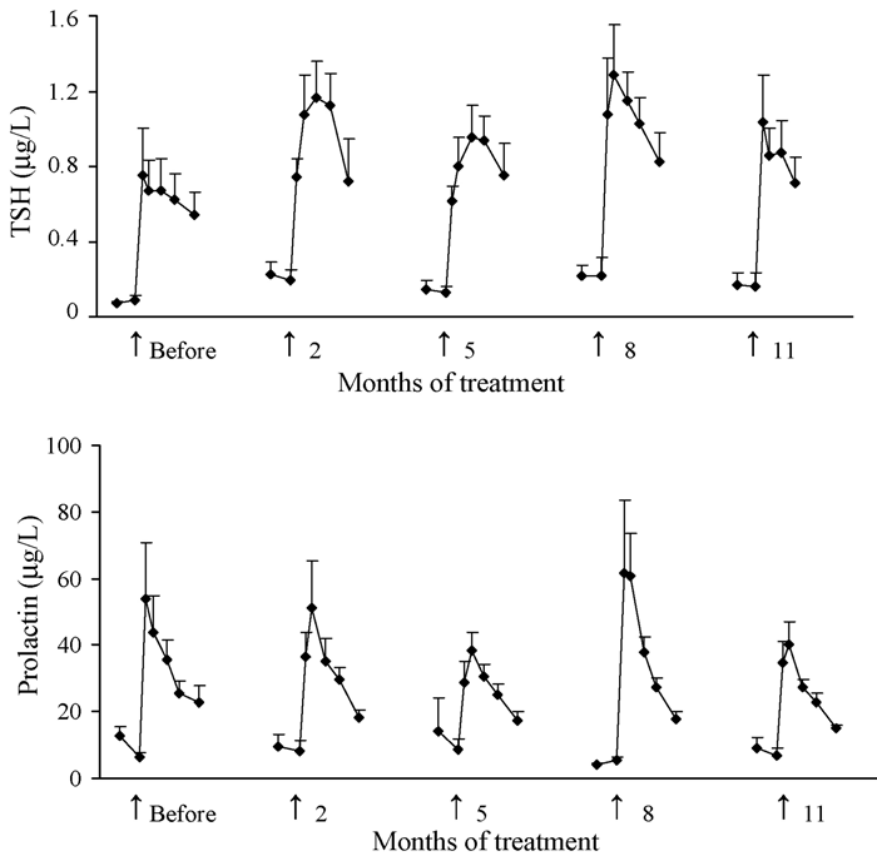

Fig. 4. Plasma TSH and prolactin responses (mean \pm S.E.M.) in five Beagle bitches in a combined anterior pituitary function test (see also legend to Fig. 1). 
subtle effects of MPA on the reproductive axis may have been missed, the prevention of estrus by MPA in the present study cannot be ascribed to a significant reduction in circulating levels of either FSH or LH. On the contrary, during the first months of MPA treatment there was an increase in basal plasma FSH without a concomitant change in basal plasma LH. The progestin-induced change in FSH concentration was not observed by Colon et al. [4] and its recognition may be explained by the repeated sampling employed in the present study.

The results of this study thus indicate that the progestin-induced changes in gonadotropin release are confined to FSH secretion. One mechanism for the differential control of LH and FSH secretion is gonadal feedback. Both estradiol and inhibin can specifically suppress FSH synthesis and secretion [37,38]. Reduced secretion of these ovarian hormones can explain the elevated circulating FSH concentration during the first months of MPA treatment. On the other hand, the gonadal peptide activin specifically stimulates FSH secretion. Consequently, a temporary progestin-induced change in the secretion of activin might also explain the initial divergent basal levels of LH and FSH. Other important factors in gonadotropin control are the frequency and amplitude of GnRH pulses, which have been shown to differentially alter LH and FSH gene expression and secretion [38-40].

The elevated basal plasma FSH level during the first months of MPA treatment may thus be due to a direct inhibitory effect of MPA at the ovarian level, resulting in suppression of the ovarian secretion of estradiol or inhibin, or stimulation of activin release. In this context, increased plasma gonadotropin levels and low ovarian estradiol production have been reported in women treated with progestins [41,42]. Observations in monkeys indicate that the inhibitory effects of progesterone on follicular development persist even in the presence of elevated plasma FSH levels, providing additional evidence that progestins may have a direct effect at the ovarian level [43]. In women, there are also indications for a hypothalamic site of progestin action [44]. An initial progestin-induced change in the pattern of hypothalamic secretion of GnRH may therefore be an alternative explanation for the rise in the basal plasma FSH level during the first months of MPA treatment observed in this study.

With continuing MPA treatment, basal plasma FSH returned to pretreatment levels and the pituitary FSH response to suprapituitary stimulation decreased. These observations may be explained by down-regulation of the pituitary GnRH receptors due to continuous GnRH stimulation [45]. The high GnRH secretion associated with MPA treatment postulated in the previous paragraph may therefore have resulted in desensitization of the response of the gonadotropes to GnRH. The decline to pretreatment FSH levels and the decrease in responsiveness of pituitary FSH secretion to GnRH are probably part of the estrus-preventing effects of MPA, because increased FSH secretion is a critical event in the initiation of ovarian folliculogenesis $[46,47]$. In other words, MPA treatment for estrus prevention may prohibit the normal rise in plasma FSH concentration during late anestrus.

The present results confirm previous findings that progestins alter the GH-IGF-1 axis in the bitch [48]. Basal plasma GH concentration tended to increase gradually during the course of the MPA treatment, but the change was not significant. In another study [17], plasma GH concentration did not rise in 27 out of 36 MPA-treated bitches. However, the significant increase in circulating IGF-I concentration during MPA treatment in the present study is consistent with excessive exposure to GH [10]. Plasma IGF-1 concentration may thus be 
a more sensitive indicator than plasma GH concentration for the effect of the progestin treatment on the GH-IGF-1 axis.

In contrast to previous observations [22], the GH response to suprapituitary stimulation prior to MPA treatment was not significant. This may be due to ageing [49], since the dogs in our study were considerably older than those in the study of Meij et al. [22]. In addition, a relatively high plasma $\mathrm{GH}$ level before suprapituitary stimulation in one of the dogs, probably explained by sampling during a GH pulse, had a substantial influence on basal plasma GH concentration. In agreement with previous observations [9], there was no pituitary GH response to suprapituitary stimulation during MPA treatment in three of the four tests. This may be ascribed to the negative feedback effect of the nonepisodically secreted mammary GH. It has been demonstrated in humans that GH exerts its negative feedback effect by stimulating hypothalamic somatostatin secretion [50]. Additionally, the GH-induced elevated circulating IGF-1 levels also inhibit pituitary GH secretion [51].

In addition to interacting with the progesterone receptor, MPA also has a relatively high affinity for the glucocorticoid receptor [16]. Suppression of the HPA axis was thus expected during MPA treatment, as was reported in both humans [52] and dogs [16,53]. Indeed, we found the cortisol response to stimulation to be decreased with MPA treatment, although ACTH secretion was only slightly affected, possible because MPA affects the HPA axis for only 2-3 weeks [53]. Although this leads to adrenocortical atrophy [14], by 3 weeks [53] or 4 weeks (present study) after administration of MPA, the initially suppressed ACTH (and cortisol) concentrations can have returned to normal.

MPA treatment causes significant increases in body weight. The intrinsic glucocorticoid properties of MPA [16], leading to increased appetite, may have contributed to this increase in body weight. However, it is difficult to attribute this effect to the glucocorticoid action of MPA alone, since treatment with MPA also affected the GH-IGF-1-axis.

As the luteal phase in the bitch progresses, circulating progesterone concentration decreases and prolactin secretion increases [54]. This association has also been demonstrated in pregnant and pseudopregnant bitches [55,56]. Moreover, administration of a progesterone-receptor antagonist to pregnant bitches causes plasma prolactin levels to rise sharply [57]. Nevertheless, in agreement with previous studies [13,17], progestin treatment did not affect prolactin secretion in the present study. This may be explained by the persistently high progestin status.

Mean basal plasma TSH concentration was higher at 8 months after the start of MPA treatment than it was before treatment and at 5 months after the start of treatment. There were no significant alterations in the TSH response to suprapituitary stimulation. Although basal plasma TSH concentrations were elevated at 8 months after the start of the treatment, they were still within the reference range for TSH in our laboratory. Others found that MPA treatment had no effect on mean circulating TSH levels [20], but several authors have reported that total T4 and/or T3 values increase during the progesteronedominated luteal phase and pregnancy in bitches [58-60]. It remains to be seen whether these changes have clinical significance, but the results of the present study emphasize the importance of considering progestin use when studying the hypothalamic-pituitary-thyroid axis.

In conclusion, MPA successfully prevented the occurrence of estrus, ovulation, and a subsequent luteal phase. The effects of chronic MPA treatment on adenohypophyseal 
function included increased FSH secretion, unaffected LH secretion, activation of the mammary GH-induced IGF-I secretion, slightly activated TSH secretion, suppression of the HPA axis, and unaffected secretion of prolactin and $\alpha-\mathrm{MSH}$.

\section{Acknowledgements}

The authors are grateful for the technical assistance of Mr. H.G.H. van Engelen, Mrs. D.M. Blankenstein, Ms. C.H.Y. Oei, Mrs. E. De Wolf, Mrs. G. De Clercq, Mr. F. Riemers, Mrs. J. Wolfswinkel, Mrs. C.P.M. Sprang, Mrs. A. Slob, and Mr. M. Coryn. The critical reading of the manuscript by Prof. Dr. J. Rothuizen, Prof. Dr. A. Rijnberk, and Dr. B.E. Belshaw is highly appreciated.

\section{References}

[1] Schaefers-Okkens AC. Ovaries. In: Rijnberk A, editor. Clinical endocrinology of dogs and cats. Dordrecht/Boston: Kluwer Academic Publishers; 1996. p. 131-56.

[2] Romagnoli S, Concannon PW. Clinical use of progestins in bitches and queens. In: Concannon PW, England G, Verstegen J, Linde-Forsberg C, editors. Recent advances in small animal reproduction. Ithaca, New York, USA: International Veterinary Information Service; 2003. www.ivis.org.

[3] McCann JP, Altszuler N, Hampshire J, Concannon PW. Growth hormone, insulin, glucose, cortisol, luteinizing hormone, and diabetes in Beagle bitches treated with medroxyprogesterone acetate. Acta Endocrinol (Copenh) 1987;116:73-80.

[4] Colon J, Kimball M, Hansen B, Concannon PW. Effects of contraceptive doses of the progestagen megestrol acetate on luteinizing hormone and follicle-stimulating hormone secretion in female dogs. J Reprod Fertil 1993;47(Suppl):519-21.

[5] Mishell Jr DR. Pharmacokinetics of depot medroxyprogesterone acetate contraception. J Reprod Med 1996;41(Suppl 5):381-90.

[6] Jain J, Dutton C, Nicosia A, Wajszczuk C, Bode FR, Mishell Jr DR. Pharmacokinetics, ovulation suppression and return to ovulation following a lower dose subcutaneous formulation of Depo-Provera ${ }^{\circledR}$. Contraception 2004;70:11-8.

[7] Ismael AAA, El-Faras A, Rocca M, El-Sibai FA, Toppozada M. Pituitary response to LHRH in long-term users of injectable contraceptives. Contraception 1987;35:487-95.

[8] Watson ADJ, Rutteman GR, Rijnberk A, Mol JA. Effects of somatostatin analogue SMS 201-995 and antiprogestin agent RU486 in canine acromegaly. Front Horm Res 1987;17:193-8.

[9] Selman PJ, Mol JA, Rutteman GR, Rijnberk A. Progestins and growth hormone excess in the dog. Acta Endocrinol 1991;125(Suppl):42-7.

[10] Selman PJ, Mol JA, Rutteman GR, Rijnberk A. Progestin treatment in the dog. I. Effects on growth hormone, IGF-I, and glucose homeostasis. Eur J Endocrinol 1994;131:413-21.

[11] Selman PJ, Mol JA, Rutteman GR, Van Garderen E, Rijnberk A. Progestin-induced growth hormone excess in the dog originates in the mammary gland. Endocrinology 1994;134:287-92.

[12] Van Garderen E, De Wit M, Voorhout WF, Rutteman GR, Mol JA, Nederbragt H, et al. Expression of growth hormone in canine mammary tissue and mammary tumors: Evidence for a potential autocrine/ paracrine stimulatory loop. Am J Pathol 1997;150:1037-47.

[13] Rutteman GR, Stolp R, Rijnberk A, Loeffler S, Bakker JA, Bevers MM, et al. Medroxy-progesterone acetate administration to ovariohysterectomized, oestradiol-primed Beagle bitches. Effect on secretion of growth hormone, prolactin and cortisol. Acta Endocrinol 1987;114:275-82.

[14] Selman PJ, Mol JA, Rutteman GR, van Garderen E, van den Ingh TS, Rijnberk A. Effects of progestin administration on the hypothalamic-pituitary-adrenal axis and glucose homeostasis in dogs. J Reprod Fertil 1997;51(Suppl):345-54. 
[15] Guthrie GP, John WJ. The in vivo glucocorticoid and antiglucocorticoid actions of medroxyprogesterone acetate. Endocrinology 1980;107:1393-7.

[16] Selman PJ, Wolfswinkel J, Mol JA. Binding specificity of medroxyprogesterone acetate and proligestone for the progesterone and glucocorticoid receptor in the dog. Steroids 1996;61:133-7.

[17] Concannon PW, Altszuler N, Hampshire J, Butler WR, Hansel W. Growth hormone, prolactin, and cortisol in dogs developing mammary nodules and an acromegaly-like appearance during treatment with medroxyprogesterone acetate. Endocrinology 1980;106:1173-7.

[18] Rutteman GR, Bevers MM, Misdorp W, Van den Brom WE. Anterior pituitary function in female dogs with mammary tumors. II. Prolactin. Anticancer Res 1989;9:241-5.

[19] Jones JR, DelRosaria L, Soriero AA. Adrenal function in patients receiving medroxyprogesterone acetate. Contraception 1974;10:1-12.

[20] Frank DW, Kirton KT, Murchison TE, Quinlan WJ, Coleman ME, Gilbertson TJ, et al. Mammary tumors and serum hormones in the bitch treated with medroxyprogesterone acetate or progesterone for four years. Fertil Steril 1979;31:340-6.

[21] Mishell Jr DR, Kletzky OA, Brenner PF, Roy S, Nicoloff J. The effect of contraceptive steroids on hypothalamic-pituitary function. Am J Obstet Gynecol 1977;128:60-74.

[22] Meij BP, Mol JA, Hazewinkel HAW, Bevers MM, Rijnberk A. Assessment of a combined anterior pituitary function test in Beagle dogs: rapid sequential intravenous administration of four hypothalamic releasing hormones. Domest Anim Endocrinol 1996;13:161-70.

[23] Meij BP, Mol JA, Rijnberk A. Thyroid-stimulating hormone responses after single administration of thyrotropin-releasing hormone and combined administration of four hypothalamic releasing hormones in Beagle dogs. Domest Anim Endocrinol 1996;13:465-8.

[24] Henry M, Figueiredo AE, Palhares MS, Coryn M. Clinical aspects of the oestrous cycle in donkeys (Equus asinus). J Reprod Fertil 1987;35(Suppl):297-303.

[25] Bosje JT, Kooistra HS, Mol JA, Voorhout G, Rijnberk A. Plasma concentrations of ACTH precursors correlate with pituitary size and resistance to dexamethasone in dogs with pituitary-dependent hyperadrenocorticism. Domest Anim Endocrinol 2002;22:201-10.

[26] Hodgkinson SC, Allolio B, Landon J, Lowry PJ. Development of a non-extracted 'two-site' immunoradiometric assay for corticotrophin utilizing extreme amino- and carboxy-terminally directed antibodies. Biochem $\mathrm{J}$ 1984;218:703-11.

[27] Findling JW, England WC, Raff H. Emerging techniques: the use of immunoradiometric assay for the measurement of ACTH in human plasma. Trends Endocrinol Metab 1990;6:283.

[28] Galac S, Kooistra HS, Voorhout G, Van den Ingh TSGAM, Mol JA, Van den Berg G, et al. Hyperadrenocorticism in a dog due to ectopic secretion of adrenocorticotropic hormone. Domest Anim Endocrinol 2005;28:338-48.

[29] Favier RP, Mol JA, Kooistra HS, Rijnberk A. Large body size in the dog is associated with transient GH excess at a young age. J Endocrinol 2001;170:479-84.

[30] Nett TM, Akbar AM, Phemister RD, Holst PA, Reichert Jr LE, Niswender GD. Levels of luteinizing hormone, estradiol and progesterone in serum during the estrous cycle and pregnancy in the Beagle bitch. Proc Soc Exp Biol Med 1975;148:134-9.

[31] Dieleman SJ, Bevers MM. Effects of monoclonal antibody against PMSG administered shortly after the preovulatory LH surge on time and number of ovulations in PMSG/PG-treated cows. J Reprod Fertil 1987;81:533-42.

[32] Mol JA, Slob A, Middleton DJ, Rijnberk A. Release of adrenocorticotropin, melanotropin and beta-endorphin by pituitary tumours of dogs with pituitary-dependent hyperadrenocorticism. Front Horm Res 1987;17:6170 .

[33] Okkens AC, Bevers MM, Dieleman SJ, Willemse AH. Shortening of the interoestrous interval and the lifespan of the corpus luteum of the cyclic dog by bromocriptine treatment. Vet Quart 1985;7:173-6.

[34] Kooistra HS, Diaz-Espineira M, Mol JA, Van Den Brom WE, Rijnberk A. Secretion pattern of thyroidstimulating hormone in dogs during euthyroidism and hypothyroidism. Domest Animal Endocrinol 2000;18:19-29.

[35] Chaffaux S, Chassagnite F, Thibier M. Concentration of LH après stimulation par la gonadoliberine (LRH) chez la chienne et effet de l'ovariectomie. Rec Med Vet 1981;10:725-33. 
[36] Cooper GS, Thorp Jr JM. FSH levels in relation to hysterectomy and to unilateral oophorectomy. Obstet Gynecol 1999;94:969-72.

[37] Mann GE, Campbell BK, McNeilly AS, Baird DT. The role of inhibin and oestradiol in the control of FSH secretion in the sheep. J Endocrinol 1992;133:381-91.

[38] Shupnik MA. Gonadal hormone feedback on pituitary gonadotropin genes. Trends Endocrinol Metab 1996;7:272-6.

[39] Haisenleder DJ, Dalkin AC, Ortolano GA, Marshall JC, Shupnik MA. A pulsatile gonadotropin-releasing hormone stimulus is required to increase transcription of the gonadotropin subunit genes: evidence for differential regulation of transcription by pulse frequency in vivo. Endocrinology 1991;128:509-17.

[40] Vizcarra JA, Wettemann RP, Braden TD, Turzillo AM, Nett TM. Effect of gonadotropin-releasing hormone $(\mathrm{GnRH})$ pulse frequency on serum and pituitary concentrations of luteinizing hormone and follicle-stimulating hormone, GnRH receptors, and messenger ribonucleic acid for gonadotropin subunits in cows. Endocrinology 1997;138:594-601.

[41] Poindexter A, Didly A, Brodyand S, Snabes M. The effects of a long-acting progestin on the hypothalamic-pituitary-ovarian axis in women with normal menstrual cycles. Contraception 1993;48:37-45.

[42] Heikinheimo O, Gordon K, Williams RF, Hodgen GD. Inhibition of ovulation by progestin analogs (agonists vs antagonists): preliminary evidence for different sites and mechanisms of actions. Contraception 1996;53:55-64.

[43] Goodman A, Hodgen G. Antifollicular action of progesterone despite hypersecretion of FSH in monkeys. Am J Physiol 1982;243:E387-97.

[44] Couzinet B, Schaison G. The control of gonadotropin secretion by ovarian steroids. Hum Reprod 1993;8:97-101.

[45] Belchetz PE, Plant TM, Nakai Y, Keogh EJ, Knobil E. Hypophyseal responses to continuous and intermittent delivery of hypothalamic gonadotropin-releasing hormone. Science 1978;202:631-2.

[46] Kooistra HS, Okkens AC, Bevers MM, Poppsnijders C, Van Haaften B, Dieleman SJ, et al. Concurrent pulsatile secretion of luteinizing hormone and follicle-stimulating hormone during different phases of the estrous cycle and anestrus in Beagle bitches. Biol Reprod 1999;60:65-71.

[47] Kooistra HS, Okkens AC, Bevers MM, Popp-Snijders C, van Haaften B, Dieleman SJ, et al. Bromocriptineinduced premature oestrus is associated with changes in the pulsatile secretion pattern of follicle-stimulating hormone in Beagle bitches. J Reprod Fertil 1999;117:387-93.

[48] Eigenmann JE, Rijnberk A. Influence of medroxyprogesterone acetate (Provera) on plasma growth hormone levels and on carbohydrate metabolism. I. Studies in the ovariohysterectomized bitch. Acta Endocrinol 1981;98:599-602.

[49] Bhatti SFM, De Vlieger SP, Van Ham L, Kooistra HS. Effects of growth hormone-releasing peptides in healthy dogs and in dogs with pituitary-dependant hyperadrenocorticism. Mol Cell Endocrinol 2002;197:97-103.

[50] Berelowitz M, Szabo M, Frohman LH, Firestone S, Chu L, Hintz RL. Somatomedin-C mediates growth hormone negative feedback by effects on both the hypothalamus and the pituitary. Science 1981;212: 1279-81.

[51] Hartman ML, Clayton PE, Johnson ML, Celniker A, Perlman AJ, Alberti KGMM, et al. A low dose euglygemic infusion of recombinant human insulin-like growth factor I rapidly suppresses fasting-enhanced pulsatile growth hormone secretion in humans. J Clin Invest 1993;91:2453-62.

[52] Willemse PHB, Dikkeschei LD, Tjabbes T, Vanveelen H, Sleijfer DT. Adrenal steroids as parameters of the bioavailability of MA and MPA. Eur J Cancer 1990;26:359-62.

[53] Selman PJ, Mol JA, Rutteman GR, Rijnberk A. Progestin treatment in the dog. II. Effects on the hypothalamic-pituitary-adrenal axis. Eur J Endocrinol 1994;131:422-30.

[54] Kooistra HS, Okkens AC. Secretion of growth hormone and prolactin during progression of the luteal phase in healthy dogs: a review. Mol Cell Endocrinol 2002;197:167-72.

[55] Steinetz BG, Goldsmith LT, Hasan SH, Lust G. Diurnal variation of serum progesterone but not relaxin, prolactin, or estradiol-17 $\beta$ in the pregnant bitch. Endocrinology 1990;127:1057-63.

[56] Okkens AC, Dieleman SJ, Kooistra HS, Bevers MM. Plasma concentrations of prolactin in overtly pseudopregnant Afghan hounds and the effect of metergoline. J Reprod Fertil 1997;51(Suppl):295-301.

[57] Galac S, Kooistra HS, Butinar J, Bevers MM, Dieleman SJ, Voorhout G, et al. Termination of mid-gestation pregnancy in bitches with aglepristone, a progesterone receptor antagonist. Theriogenology 2000;53:941-50. 
[58] Reimers TJ, Mummery LK, McCann JP, Cowan RG, Concannon PW. Effects of reproductive state on concentrations of thyroxine 3,5,3'triiodothyronine and cortisol in serum of dogs. Biol Reprod 1984;31: 148-54.

[59] Dixon RM. Canine hypothyroidism. In: Mooney CT, Peterson ME, editors. BSAVA Manual of canine and feline endocrinology. 3rd ed. Gloucester, England: British Small Animal Veterinary Association; 2004. p. 76-94.

[60] Feldman EC, Nelson RW. Hypothyroidism. In: Feldman EC, Nelson RW, editors. Canine and feline endocrinology and reproduction. St. Lois, MO, USA: Saunders; 2004. p. 86-151. 